\title{
Altering the Time of the Second Gonadotropin-Releasing Hormone Injection and Artificial Insemination (Al) During Ovsynch Affects Pregnancies per Al in Lactating Dairy Cows
}

\author{
D. J. Brusveen, A. P. Cunha, C. D. Silva, P. M. Cunha, R. A. Sterry, E. P. B. Silva, \\ J. N. Guenther, and M. C. Wiltbank ${ }^{1}$ \\ Department of Dairy Science, University of Wisconsin, Madison 53706
}

\begin{abstract}
Based on previous research, we hypothesized that Cosynch at $72 \mathrm{~h}\left[\mathrm{GnRH}-7 \mathrm{~d}-\mathrm{PGF}_{2 \alpha}-72 \mathrm{~h}-\mathrm{GnRH}+\right.$ artificial insemination (AI)] would result in a greater number of pregnancies per AI (P/AI) than Cosynch at $48 \mathrm{~h}$. Further, we hypothesized that P/AI would be improved to a greater extent when GnRH was administered at $56 \mathrm{~h}$ after $\mathrm{PGF}_{2 \alpha}$ before $\mathrm{AI}$ at $72 \mathrm{~h}$ due to a more optimal interval between the LH surge and AI. Nine hundred twenty-seven lactating dairy cows $(\mathrm{n}=$ $1,507 \mathrm{AI}$ ) were blocked by pen, and pens rotated through treatments. All cows received GnRH followed $7 \mathrm{~d}$ later by $\mathrm{PGF}_{2 \alpha}$ and then received one of the following: 1) $\mathrm{GnRH}+$ timed $\mathrm{AI} 48 \mathrm{~h}$ after $\mathrm{PGF}_{2 \alpha}$ (Cosynch48); 2) GnRH $56 \mathrm{~h}$ after $\mathrm{PGF}_{2 \alpha}+$ timed AI $72 \mathrm{~h}$ after $\mathrm{PGF}_{2 \alpha}$ (Ovsynch-56); or 3) GnRH + timed AI $72 \mathrm{~h}$ after $\mathrm{PGF}_{2 \alpha}$ (Cosynch-72). Pregnancy diagnoses were performed by ultrasound at 31 to $33 \mathrm{~d}$ post-AI and again at 52 to $54 \mathrm{~d}$ post-AI. Overall P/AI were similar for the Cosynch-48 (29.2\%) and Cosynch-72 (25.4\%) groups. The Ovsynch-56 group had a greater P/AI (38.6\%) than Cosynch-48 or Cosynch-72. Presynchronized first-service animals had greater P/AI than cows at later services in Cosynch-48 (36.2 vs. 23.0\%) and Ovsynch-56 (44.8 vs. $32.7 \%$ ) but not in Cosynch-72 (24.6 vs. $26.2 \%)$. Similarly, primiparous cows had greater P/AI than multiparous cows in Cosynch-48 (34.1 vs. $22.9 \%$ ) and Ovsynch-56 (41.3 vs. $32.6 \%)$, but not Cosynch-72 (29.8 vs. 25.3\%). In conclusion, we found no advantage to Cosynch at $72 \mathrm{~h}$ vs. $48 \mathrm{~h}$. In contrast, we found a clear advantage to treating with GnRH at $56 \mathrm{~h}, 16 \mathrm{~h}$ before a 72-h AI, probably because of more-optimal timing of AI before ovulation.
\end{abstract}

Key words: Ovsynch, Cosynch

Received June 1, 2007.

Accepted October 10, 2007.

${ }^{1}$ Corresponding author: wiltbank@wisc.edu

\section{INTRODUCTION}

Timed AI (TAI) protocols such as Ovsynch (GnRH-7 $\mathrm{d}-\mathrm{PGF}_{2 \alpha}-48-72 \mathrm{~h}-\mathrm{GnRH}$ ), have been developed to improve pregnancy rates by increasing AI submission rates. Ovsynch utilizes a final treatment with $\mathrm{GnRH}$ that synchronizes the time of ovulation within an 8-h period (Pursley et al., 1995). This precise timing of ovulation should allow optimization of the time of AI in relation to the time of ovulation. A number of studies have provided information relating to a potential optimal time of AI.

One important study on the optimal time of AI utilized the original Ovsynch protocol and then had AI performed at $0,8,16,24$, or $32 \mathrm{~h}$ after the final GnRH treatment (Pursley et al., 1998). This study found a quadratic effect of time of $\mathrm{AI}$ on number of pregnancies per AI (P/AI) with P/AI increasing from 0 to $16 \mathrm{~h}$ with a subsequent decrease at $24 \mathrm{~h}$ and a further decrease when cows received AI after the expected time of ovulation $(32 \mathrm{~h})$. Nevertheless, only AI after the expected time of ovulation ( $32 \mathrm{~h}$ after final $\mathrm{GnRH}$ ) produced a significant decrease in both percentage calving per AI and P/AI determined at the first pregnancy diagnosis (Pursley et al., 1998). Analysis of calving data suggested that $\mathrm{AI}$ at any time between 0 and $24 \mathrm{~h}$ after the final GnRH resulted in similar rates of calving. Thus, this study suggested that there may be an optimal time of $\mathrm{AI}(\sim 16 \mathrm{~h}$ after final $\mathrm{GnRH})$ but also suggested that there may be substantial flexibility in the time of $\mathrm{AI}$ in relation to ovulation, provided that $\mathrm{AI}$ was done before the time of ovulation.

Insemination near or after the time of ovulation may provide insufficient time for optimal sperm capacitation and transport and result in an aged oocyte before the sperm is capable of fertilization (Hunter and Wilmut, 1983; Wilmut and Hunter, 1984; Hawk, 1987). Alternatively, excessive time from insemination to ovulation $(>24 \mathrm{~h})$ also appears to reduce fertility. Indeed, results from the earliest (Trimberger and Davis, 1943; Trimberger, 1944) up to the most recent studies (Dransfield et al., 1998; Pursley et al., 1998; Saacke 
et al., 2000; Dalton et al., 2001) on time of AI have generally shown a decline in P/AI in cows inseminated at the onset of estrus or at the time of the LH surge (induced by GnRH treatment; Pursley et al., 1998) compared with later times. Decreases in fertilization rate have been reported when cows were inseminated at the onset of estrus compared with breeding 12 or $24 \mathrm{~h}$ later (Dalton et al., 2001). Therefore, a loss of sperm viability is likely responsible for the declines in fertilization rate and P/AI that have been observed in many (Trimberger and Davis, 1943; Trimberger, 1944; Pursley et al., 1998; Dalton et al., 2001) but not all (Portaluppi and Stevenson, 2005) studies when there were long intervals between AI and ovulation.

Despite these results, many dairies utilize a protocol in which AI is done concurrently with the final GnRH of the Ovsynch protocol, a protocol known as Cosynch (Geary and Whittier, 1998). This procedure requires one less time to lock up, identify, and handle each cow, thereby potentially decreasing labor costs, heat stress, and other cow-handling problems associated with utilizing a TAI protocol. Some studies have compared Cosynch to an Ovsynch protocol in which cows were inseminated $24 \mathrm{~h}$ after the GnRH treatment. Vasconcelos et al. (1997) found that inseminating at 24 $\mathrm{h}$ after $\mathrm{GnRH}$ improved pregnancy success compared with Cosynch at $48 \mathrm{~h}$ (Cosynch-48). In contrast, 2 recent studies utilizing only presynchronized first-service animals found no difference in P/AI for animals receiving Cosynch at $48 \mathrm{~h}$ compared with Ovsynch with a 24-h interval between GnRH and AI (Portaluppi and Stevenson, 2005; Cornwell et al., 2006). Portaluppi and Stevenson (2005) not only compared these 2 protocols in their study with presynchronized first-service animals, but also included a treatment group that received Cosynch at $72 \mathrm{~h}$ (Cosynch-72). The latter cows had better P/AI than when the results from the other 2 groups were combined, suggesting that delaying the time of final GnRH as well as the time of AI may improve Ovsynch results, at least during the first AI after Presynch. Nevertheless, the authors cautioned that this protocol had not been evaluated for synchronizing cows at second and later services (Resynch). Thus, although Cosynch has become quite popular in the dairy industry, there are conflicting results about whether this protocol produces P/AI that are similar to protocols that have AI at a time closer to the time of ovulation.

Problems with detection of estrus have led to the widespread use of TAI in the dairy industry (Caraviello et al., 2006), making optimization of TAI protocols of economic importance. In addition, the substantial variation in reproductive efficiency reported after altering the timing of the final GnRH treatment and time of $\mathrm{AI}$ in some of the previous studies suggests that substantial gain might occur from optimizing these intervals. In this study we again compared the Cosynch-48 protocol to the Cosynch-72 protocol at first AI (after Presynch) but also at later AI (Resynch). We hypothesized that Cosynch-72 would result in better P/AI than Cosynch-48 at first AI but not at later AI based on the previous results from Portaluppi and Stevenson (2005). In addition, a group was included that had the same time of AI as Cosynch-72 (72 h after $\mathrm{PGF}_{2 \alpha}$ ) but with a more optimal time of induced ovulation in relation to AI. This was done by administering the $\mathrm{GnRH}$ at $56 \mathrm{~h}$ after the $\mathrm{PGF}_{2 \alpha}$ treatment and then performing AI $16 \mathrm{~h}$ later (Ovsynch-56). We hypothesized that optimizing the time of $\mathrm{AI}$ in relation to the final GnRH of Ovsynch would increase P/AI compared with Cosynch-72 or Cosynch-48 based on previous results of Pursley et al. (1998) suggesting that $16 \mathrm{~h}$ after GnRH was the optimal time of AI during Ovsynch. Nevertheless, the interval from PGF until GnRH can also impact fertility (Peters and Pursley, 2003) and this cannot be excluded in the present experimental design.

\section{MATERIALS AND METHODS}

\section{Animals}

Nine hundred twenty-seven lactating Holstein cows, receiving a total of $1,507 \mathrm{AI}$, were housed in free-stall barns at a commercial dairy farm near Juneau, Wisconsin. Cows were milked thrice daily and fed a TMR twice daily that consisted of corn silage and alfalfa silage as forage and a corn/soybean meal-based concentrate. The TMR was formulated to meet or exceed minimum nutritional requirements for lactating dairy cows (NRC, 2001). Cows in the study started to receive bST (500 mg/dose; Posilac, Monsanto, St. Louis, MO) at about $60 \mathrm{~d}$ postpartum. Commercial frozen-thawed semen from multiple sires was used across all treatments (10 to 150 units from each sire used during the study). All injections and inseminations were performed by 1 of 5 researchers from our laboratory. The University of Wisconsin-Madison, College of Agriculture and Life Sciences Animal Care Committee approved all animal procedures.

\section{Experimental Design}

This study was conducted from August to December 2005. Cows were blocked by pen ( $\mathrm{n}=8$ pens) where all cows in one pen received the same treatment during $1 \mathrm{wk}$, and each pen rotated through the 3 treatments during a 3 -wk period. Primiparous and multiparous cows were present and intermingled in each of the 
pens. Cows ranged from 30 to 36 DIM at the start of the Presynch protocol, which consisted of 2 injections of $\mathrm{PGF}_{2 \alpha} 14 \mathrm{~d}$ apart with the second injection $11 \mathrm{~d}$ before beginning Ovsynch. Cows that had already received at least one service (whether part of the experiment or outside the experiment) were enrolled in Resynch after a nonpregnant diagnosis. All cows received $\mathrm{GnRH}(100 \mu \mathrm{g}$ of gonaderelin diacetate tetrahydrate, Ovacyst, IVX Pharmaceuticals, St. Joseph, MO), followed $7 \mathrm{~d}$ later by $\mathrm{PGF}_{2 \alpha}$ (25 $\mathrm{mg}$ of Lutalyse, Pfizer Animal Health, New York, NY), and then received one of the following: 1) GnRH + TAI $48 \mathrm{~h}$ after $\mathrm{PGF}_{2 \alpha}$ (Cosynch-48), 2) GnRH $56 \mathrm{~h}$ after $\mathrm{PGF}_{2 \alpha}+$ TAI $72 \mathrm{~h}$ after $\mathrm{PGF}_{2 \alpha}$ (Ovsynch-56), or 3) $\mathrm{GnRH}+$ TAI $72 \mathrm{~h}$ after $\mathrm{PGF}_{2 \alpha}$ (Cosynch-72). Pregnancy diagnoses were performed by ultrasound (Easi-Scan, BCF Technology Ltd., Livingston, United Kingdom) using a 7.5-MHz probe at 31 to $33 \mathrm{~d}$ post-AI and again at 52 to $54 \mathrm{~d}$ post-AI. Pregnancy loss was calculated as cows that were pregnant at the first exam and not pregnant at the second pregnancy exam. Cows diagnosed not pregnant at the first pregnancy exam were restarted on Ovsynch at 32 to $33 \mathrm{~d}$ post-AI (depending on which treatment they had received previously) with subsequent treatment assignment based on pen location of the cow. No detection of estrus was used in reproductive management at any time during the study.

\section{Statistical Analysis}

Analyses of data were performed using the GLIMMIX procedure in SAS (SAS Institute Inc., Cary, NC). Backward elimination was used to eliminate explanatory variables that were not significant $(P>0.10)$. Comparisons with means that differed at $P<0.05$ were considered significant, and $P<0.1$ was considered to be a tendency for an effect. Variables that remained in the model for comparisons of P/AI between treatments included treatment, parity, times inseminated, treatment $\times$ times inseminated, and parity $\times$ times inseminated. Sire, technician, pen, and treatment $\times$ parity were not significant, and were thus removed from the model. For comparisons of pregnancy loss, the following variables were included in the final model: treatment, parity, times inseminated, treatment $\times$ parity, and parity $\times$ times inseminated.

For Table 3, least squares means were calculated and used during comparisons. Models were run separately for first and later services. Backward elimination was used to eliminate all nonsignificant explanatory variables. For both comparisons the only remaining variables in the model were treatment and parity. No interactions were found.
Table 1. Logistic regression analyses in SAS were used to calculate $P$-values for 3 separate statistical models related to first (31-33 d) or second (52-54 d) pregnancy diagnoses, or pregnancy loss (between the 2 pregnancy diagnoses)

\begin{tabular}{lccc}
\hline & & & Pregnancy \\
& $31-33 \mathrm{~d}$ & $52-54 \mathrm{~d}$ & loss \\
\hline Treatment & $<0.001$ & $<0.001$ & 0.492 \\
Parity & $<0.001$ & $<0.001$ & 0.109 \\
Service number & 0.012 & 0.017 & 0.896 \\
Treatment $\times$ parity & $0.813^{*}$ & $0.823^{*}$ & 0.077 \\
Treatment $\times$ service number & 0.074 & 0.057 & $0.560^{*}$ \\
Parity $\times$ service number & 0.003 & 0.001 & 0.101 \\
\hline
\end{tabular}

*Denotes nonsignificant values $(P>0.1)$ that were removed from the model.

To provide the comparisons contained in Table 4, we used the raw numerical percentages and compared values using $\chi^{2}$ tests. There was an interaction between parity and service number that is demonstrated for all 3 treatment groups in Figure 1. For the comparisons in this figure, we used $\chi^{2}$ tests to compare primiparous vs. multiparous cows within each treatment group at first or later services.

\section{RESULTS}

Initially, we performed 1,507 AI during this study. However, 39 cows were eliminated from the trial before the first pregnancy diagnosis because they died or were sold. Another 12 cows were sold or died between the first and second pregnancy diagnosis, so they were not considered in calculating pregnancy loss or $\mathrm{P} / \mathrm{AI}$ at the second pregnancy exam. Therefore, 1,468 breedings were used for comparisons done at the first pregnancy diagnosis, and 1,456 breedings were used in calculations done at the second pregnancy diagnosis and for pregnancy loss. An unusually large percentage of cows that were confirmed pregnant at the second pregnancy diagnosis were sold, died, or aborted before calving, leaving only 311 cows $(77.3 \%$ of those confirmed pregnant at 52 to $54 \mathrm{~d}$ ) for comparison of calf sex ratio.

The $P$-values obtained are shown in Table 1 for the models used to calculate P/AI for pregnancy diagnoses at 31 to $33 \mathrm{~d}$ or 52 to $54 \mathrm{~d}$ after $\mathrm{AI}$ and for pregnancy loss. An overall effect of treatment on P/AI at either pregnancy diagnosis was detected but no effect of treatment on pregnancy loss was found. In addition, parity affected P/AI with primiparous cows, having an overall greater P/AI than multiparous cows at the 31 to $33 \mathrm{~d}$ pregnancy diagnosis ( 36.9 vs. $25.4 \%$, respectively; $P<0.001)$ and the 52 to $54 \mathrm{~d}$ pregnancy diagnosis $(33.5$ vs. $23.8 \% ; P<0.001)$. There was also a tendency $(P=0.109)$ for an effect of parity on pregnancy loss, with primiparous cows tending to have greater overall pregnancy losses than multiparous cows (7.3 
vs. 2.8\%). Service number also affected P/AI with cows receiving first service having more P/AI than cows receiving later services at either the 31 to $33 \mathrm{~d}$ (34.7 vs. $27.2 \% ; P=0.012)$ or the 52 to $54 \mathrm{~d}(32.0$ vs. $25 \% ; P=$ $0.017)$ pregnancy diagnosis. There was a tendency for a treatment by parity interaction in pregnancy loss but not in P/AI. An interaction between treatment and service number also tended to affect P/AI but not pregnancy loss. In addition, there was a parity by service number interaction resulting from a much greater $\mathrm{P} /$ AI for first-service primiparous cows (46.4\%) compared with first-service multiparous (24.6\%), repeat-service primiparous $(28.2 \%)$, or repeat-service multiparous $(26.2 \%)$ cows.

Table 2 shows the overall treatment effects on P/AI, pregnancy loss, and calf sex ratio. At the first pregnancy diagnosis, P/AI were similar $(P>0.1)$ for Cosynch-48 (29.2\%) and Cosynch-72 (25.4\%); however, Ovsynch-56 cows had greater P/AI (38.6\%) than Cosynch-48 $(P<0.03)$ or Cosynch-72 $(P<0.001)$ cows. At the second pregnancy diagnosis, Ovsynch-56 continued to have more P/AI (36.0\%) than Cosynch-48 $(27.2 \% ; P<0.04)$ or Cosynch-72 (22.9\%; $P<0.001)$, with no difference between Cosynch-48 and Cosynch$72(P>0.1)$. Pregnancy loss was relatively low for all groups during this time (overall average of 5.6\%) and did not differ by treatment. Calf sex ratio did not vary between groups. Table 3 separates the treatment effects for cows at first and later services. Cows at first service had more P/AI than cows at later services in Cosynch-48 (36.2 vs. 23.0\%; $P=0.024)$ and tended to be greater in Ovsynch-56 (44.8 vs. $32.7 \% ; P=0.074$ ) but not in Cosynch-72 (24.6 vs. $26.2 \% ; P>0.1$ ) at the first pregnancy diagnosis. Similarly, at the second

Table 2. Overall pregnancies per AI (P/AI) for Cosynch-48, Ovsynch56 , and Cosynch-72 at the 2 pregnancy diagnoses, and pregnancy loss for the 3 treatment groups

\begin{tabular}{lccc}
\hline & \multicolumn{3}{c}{ Treatment } \\
\cline { 2 - 4 } Item & Cosynch-48 & Ovsynch-56 & Cosynch-72 \\
\hline P/AI 31-33 d (\%) & 26.7 & 36.1 & 27.3 \\
(n/n) & $(132 / 494)$ & $(165 / 457)$ & $(141 / 517)$ \\
Least squares estimate & $29.2^{\mathrm{a}}$ & $38.6^{\mathrm{b}}$ & $25.4^{\mathrm{a}}$ \\
P/AI 52-54 d (\%) & 25.2 & 33.3 & 25.0 \\
(n/n) & $(124 / 493)$ & $(150 / 450)$ & $(128 / 513)$ \\
Least squares estimate & $27.2^{\mathrm{a}}$ & $36.0^{\mathrm{b}}$ & $22.9^{\mathrm{a}}$ \\
Pregnancy loss (\%) & 5.3 & 5.1 & 6.6 \\
(n/n) & $(7 / 131)$ & $(8 / 158)$ & $(9 / 137)$ \\
Calf sex ratio 1 (F:M) & $43: 57$ & $48: 52$ & $42: 58$ \\
(n) & $(91)$ & $(115)$ & $(105)$ \\
\hline
\end{tabular}

${ }^{\mathrm{a}, \mathrm{b}}$ Means within a row with different superscripts differ $(P<0.05)$.

${ }^{1}$ Calf sex ratio was determined based on data taken at calving. A large percentage of cows were sold or died between the second pregnancy diagnosis and calving. pregnancy diagnosis, P/AI remained greater for cows receiving first service compared with cows at later services in the Cosynch-48 (34.3 vs. $21.7 \% ; P=0.044)$ and Ovsynch-56 (42.6 vs. $29.6 \% ; P=0.039)$ groups, but was not different $(P>0.1)$ in the Cosynch-72 group. At either first service or later services the Ovsynch56 group had the numerically greatest P/AI. The P/AI for Ovsynch-56 was statistically greater than Cosynch72 at first service $(P=0.006$ and $P=0.003$ for first and second pregnancy diagnosis) but not later services. However, the P/AI for Ovsynch-56 was statistically greater than Cosynch-48 at later services $(P=0.008$ and $P=0.027$ for first and second pregnancy diagnosis) but not at first service. All groups had similar pregnancy losses.

Treatment by parity effects are shown in Table 4 . Primiparous cows had a greater P/AI than multiparous cows in Cosynch-48 (34.1 vs. $22.9 \% ; P=0.009)$ and Ovsynch-56 (41.3 vs. $32.6 \% ; P=0.065)$ but not Cosynch-72 (29.8 vs. $25.3 \% ; P=0.264)$ at the first pregnancy diagnosis. At the second pregnancy diagnosis, only primiparous cows in the Cosynch-48 group had significantly more P/AI than multiparous cows (30.5 vs. $22.4 \% ; P=0.05$ ). Within a parity, there continued to be treatment differences that were consistent with the overall treatment effects in Table 2 . Cows receiving Ovsynch-56 had numerically greater P/AI in both primiparous and multiparous cows, with Ovsynch-56 greater than Cosynch-72 in primiparous cows $(P=$ 0.015 and $P=0.059$ for first and second pregnancy diagnosis) and Ovsynch-56 greater than Cosynch-48 $(P=0.008$ and $P=0.015)$ and Cosynch-72 $(P=0.051$ and $P=0.026$ ) in multiparous cows at first and second pregnancy diagnoses. The tendency for a parity effect and treatment $\times$ parity interaction on pregnancy loss can be observed from the numerically greater pregnancy loss in primiparous than multiparous cows and within multiparous cows at the Cosynch-72 compared with the Cosynch-48 and Ovsynch-56 cows. Pregnancy loss was greater for primiparous than multiparous cows in the Cosynch-48 and Ovsynch-56 groups but not in Cosynch-72 $(P=0.02, P=0.016$, and $P>0.1$, respectively).

Figure 1 summarizes the interactions between parity and times inseminated. At first service the primiparous cows had a greater P/AI than the multiparous cows in all treatment groups. In contrast, at second or later services there was no difference between primiparous and multiparous cows for any of the treatment groups. Nevertheless, the Ovsynch-56 cows always had numerically the greatest P/AI when compared at similar parities and services to Cosynch-48 and Cosynch-72 cows. 
Table 3. Comparison of pregnancies per AI (P/AI) and pregnancy loss between treatments for first or later services

\begin{tabular}{|c|c|c|c|c|c|c|}
\hline \multirow[b]{2}{*}{ Item } & \multicolumn{3}{|c|}{ First service } & \multicolumn{3}{|c|}{ Later service } \\
\hline & Cosynch-48 & Ovsynch-56 & Cosynch-72 & Cosynch-48 & Ovsynch-56 & Cosynch-72 \\
\hline $\begin{array}{l}\text { P/AI 31-33 d (\%) } \\
(\mathrm{n} / \mathrm{n})\end{array}$ & $\begin{array}{l}38.0 \\
(41 / 108)\end{array}$ & $\begin{array}{l}45.2 \\
(52 / 115)\end{array}$ & $\begin{array}{l}27.5 \\
(33 / 120)\end{array}$ & $\begin{array}{l}23.6 \\
(91 / 386)\end{array}$ & $\begin{array}{c}33.0 \\
(113 / 342)\end{array}$ & $\begin{array}{c}27.2 \\
(108 / 397)\end{array}$ \\
\hline $\begin{array}{l}\text { Least squares estimate } \\
\text { P/AI } 52-54 \mathrm{~d}(\%) \\
(\mathrm{n} / \mathrm{n}) \\
\text { Least squares estimate }\end{array}$ & $\begin{array}{l}36.2^{\mathrm{ab}} \\
35.2 \\
(38 / 108) \\
34.3^{\mathrm{A}, \mathrm{ab}}\end{array}$ & $\begin{array}{l}44.8^{\mathrm{a}} \\
43.4 \\
(49 / 113) \\
42.6^{\mathrm{a}}\end{array}$ & $\begin{array}{l}24.6^{\mathrm{b}} \\
24.6 \\
(29 / 118) \\
21.7^{\mathrm{B}, \mathrm{b}}\end{array}$ & $\begin{array}{l}23.0^{\mathrm{y}} \\
22.3 \\
(86 / 385) \\
21.7^{\mathrm{y}}\end{array}$ & $\begin{array}{c}32.7^{\mathrm{z}} \\
30.0 \\
(101 / 337) \\
29.6^{\mathrm{z}}\end{array}$ & $\begin{array}{l}26.2^{\mathrm{yz}} \\
25.1 \\
(99 / 395) \\
24.1^{\mathrm{yz}}\end{array}$ \\
\hline $\begin{array}{l}\text { Pregnancy loss }(\%) \\
(\mathrm{n} / \mathrm{n}) \\
\text { Least squares estimate }\end{array}$ & $\begin{array}{l}7.3 \\
(3 / 41) \\
9.3\end{array}$ & $\begin{array}{l}2.0 \\
(1 / 50) \\
8.4\end{array}$ & $\begin{array}{l}6.5 \\
(2 / 31) \\
5.0\end{array}$ & $\begin{array}{l}4.4 \\
(4 / 90) \\
1.6\end{array}$ & $\begin{array}{l}6.5 \\
(7 / 108) \\
1.4\end{array}$ & $\begin{array}{l}6.6 \\
(7 / 106) \\
9.4\end{array}$ \\
\hline
\end{tabular}

\section{DISCUSSION}

This study tested 2 hypotheses that were proposed based on previous studies that have attempted to optimize TAI protocols. The first hypothesis was that delaying the time of the second $\mathrm{GnRH}$ and $\mathrm{AI}$ to $72 \mathrm{~h}$ after the $\mathrm{PGF}_{2 \alpha}$ treatment in a Cosynch program would result in a greater P/AI than a 48-h Cosynch program when tested at the first AI but not at second or later services. This hypothesis was based on the results of Portaluppi and Stevenson (2005) who reported a greater P/AI for a Cosynch-72 (31.4\%) than for a Cosynch-48 (22.8\%) program. Our results did not support this hypothesis. Surprisingly, we found that P/AI was similar for Cosynch-48 and Cosynch-72 when evaluating only Resynch services. However, at first service, Cosynch-48 tended to have greater P/AI $(P=0.09)$ than Cosynch-72. As discussed below, we also found some intriguing relationships with parity and service number in our data but none of this information provided any support for this first hypothesis.
In contrast, we found strong support for our second hypothesis that optimizing the time of AI, in relation to the expected time of ovulation, would increase P/AI compared with a Cosynch protocol. The time of AI was identical for the Cosynch-72 and Ovsynch-56 groups (AI at $72 \mathrm{~h}$ after $\mathrm{PGF}_{2 \alpha}$ treatment) and therefore any difference between these groups was due to the earlier GnRH injection in the Ovsynch-56 cows. This change would result in a shorter time from AI until ovulation ( $12 \mathrm{~h}$ ) compared with the Cosynch-72 cows ( 28 h). The dramatic reduction in P/AI following Cosynch makes good physiological sense based on the limited life span of sperm and a probable reduction in fertilization rate after a prolonged time from placing frozenthawed sperm in the reproductive tract until ovulation (Dalton et al., 2001). These data are also consistent with previous studies that have found improvements in fertility when cows were inseminated at 8 to $16 \mathrm{~h}$ before ovulation compared with times that were longer or shorter than this interval (Trimberger and Davis,

Table 4. Differences in pregnancies per AI (P/AI) and pregnancy loss based on treatment and parity

\begin{tabular}{|c|c|c|c|c|c|c|}
\hline \multirow[b]{2}{*}{ Item } & \multicolumn{3}{|c|}{ Primiparous } & \multicolumn{3}{|c|}{ Multiparous } \\
\hline & Cosynch-48 & Ovsynch-56 & Cosynch-72 & Cosynch-48 & Ovsynch-56 & Cosynch-72 \\
\hline $\begin{array}{l}\text { P/AI 31-33 d (\%) } \\
(\mathrm{n} / \mathrm{n})\end{array}$ & $\begin{array}{l}34.1^{\mathrm{ab}} \\
(57 / 167)\end{array}$ & $\begin{array}{l}41.3^{\mathrm{a}} \\
(76 / 184)\end{array}$ & $\begin{array}{l}29.8^{\mathrm{b}} \\
(67 / 225)\end{array}$ & $\begin{array}{l}22.9^{\mathrm{y}} \\
(75 / 327)\end{array}$ & $\begin{array}{l}32.6^{\mathrm{z}} \\
(89 / 273)\end{array}$ & $\begin{array}{l}25.3^{\mathrm{y}} \\
(74 / 292)\end{array}$ \\
\hline $\begin{array}{l}\text { P/AI 52-54 d (\%) } \\
(\mathrm{n} / \mathrm{n})\end{array}$ & $\begin{array}{c}30.5^{\mathrm{AB}} \\
(51 / 167)\end{array}$ & $\begin{array}{l}36.5^{\mathrm{A}} \\
(66 / 181)\end{array}$ & $\begin{array}{l}27.7^{\mathrm{B}} \\
(62 / 224)\end{array}$ & $\begin{array}{l}22.4^{\mathrm{y}} \\
(73 / 326)\end{array}$ & $\begin{array}{l}31.2^{\mathrm{z}} \\
(84 / 269)\end{array}$ & $\begin{array}{l}22.8^{y} \\
(66 / 289)\end{array}$ \\
\hline $\begin{array}{l}\text { Pregnancy loss (\%) } \\
(\mathrm{n} / \mathrm{n})\end{array}$ & $\begin{array}{l}10.5 \\
(6 / 57)\end{array}$ & $\begin{array}{l}9.6 \\
(7 / 73)\end{array}$ & $\begin{array}{l}6.1 \\
(4 / 66)\end{array}$ & $\begin{array}{l}1.3^{\mathrm{Y}} \\
(1 / 75)\end{array}$ & $\begin{array}{l}1.2^{\mathrm{Y}} \\
(1 / 85)\end{array}$ & $\begin{array}{l}7.0^{\mathrm{Z}} \\
(5 / 71)\end{array}$ \\
\hline
\end{tabular}

${ }^{\mathrm{a}, \mathrm{b}}$ Means within a row for primiparous animals with different superscripts differ $(P<0.05)$.

${ }^{\mathrm{y}, \mathrm{z}}$ Means within a row for multiparous animals with different superscripts differ $(P<0.05)$.

$\mathrm{A}, \mathrm{B}$ Means within a row for primiparous animals with different superscripts tend to differ $(P<0.1)$.

${ }_{\mathrm{Y}, \mathrm{Z}}$ Means within a row for multiparous animals with different superscripts tend to differ $(P<0.1)$. 

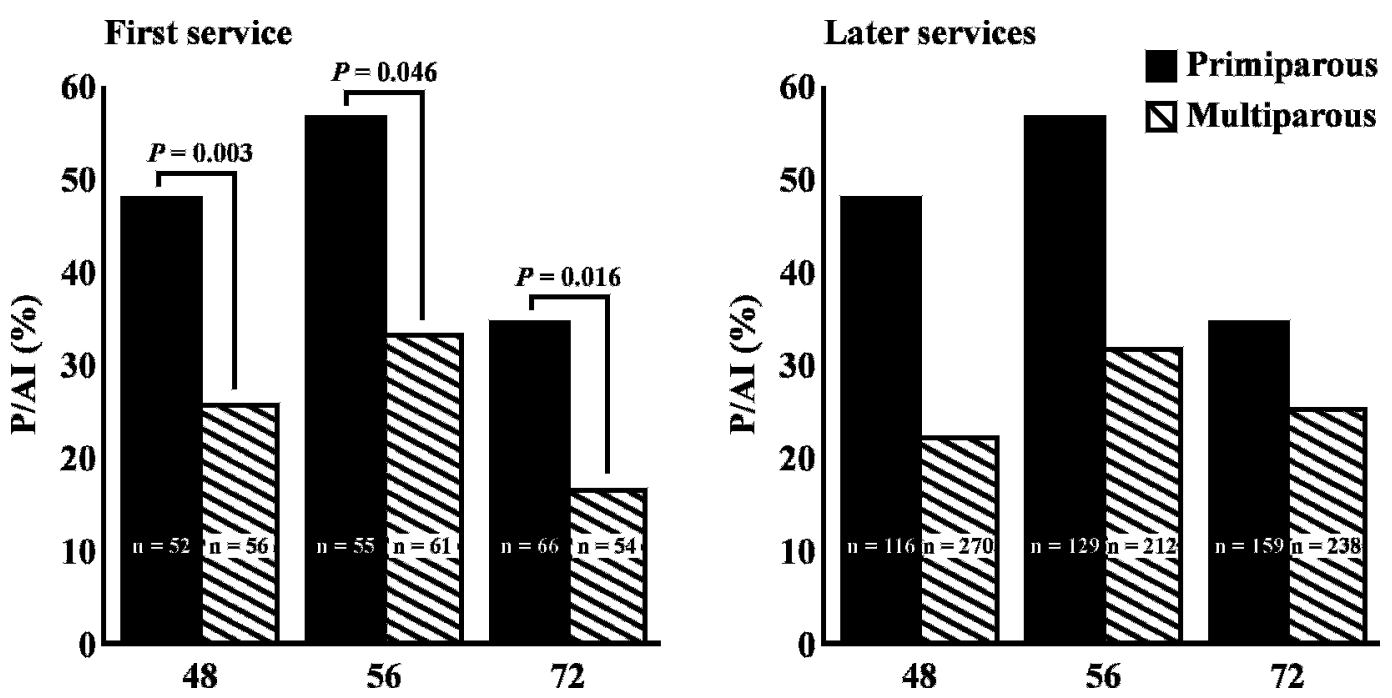

Figure 1. Comparisons of primiparous vs. multiparous cows in the 3 treatment groups during first service (left side) or later services (right side). Primiparous cows had higher pregnancies per AI (P/AI) than multiparous cows at first service, but there was no difference in P/AI between primiparous and multiparous animals for later services.

1943; Trimberger, 1944; Pursley et al., 1998). For example, Dransfield et al. (1998) used the HeatWatch estrus detection system and found that animals inseminated between 8 and $12 \mathrm{~h}$ following onset of estrus had the most P/AI, but insemination at any time between 4 and $16 \mathrm{~h}$ produced similar P/AI, with AI later than 16 $\mathrm{h}$ after the onset of estrus producing much lower $\mathrm{P} /$ $\mathrm{AI}$, and AI between 0 and $4 \mathrm{~h}$ after onset of estrus producing only somewhat lower P/AI. As discussed previously, Pursley et al. (1998) found a quadratic effect of time of AI after the second GnRH of Ovsynch on P/AI, with $16 \mathrm{~h}$ producing the greatest fertility.

More intensive studies have also provided support for optimizing the time of $\mathrm{AI}$ in relation to ovulation. For example, a previous study (Dalton et al., 2001) using the HeatWatch estrus detection system for precise determination of the onset of estrus compared P/AI for animals inseminated when estrus was first detected or at 12 or $24 \mathrm{~h}$ after the onset of estrus. The results indicated that fertilization rate was positively correlated with a greater accessory sperm number, with those animals receiving $\mathrm{AI}$ at $24 \mathrm{~h}$ after the onset of estrus having the greatest fertilization rate, and those inseminated at the onset of estrus having the lowest (Dalton et al., 2001). Artificial insemination at $24 \mathrm{~h}$ following estrus detection also produced the lowest quality embryos, potentially due to an aged oocyte at the time of fertilization. This is possible because ovulation occurs approximately $28 \mathrm{~h}$ after the onset of estrus (Walker et al., 1996), and the time required for sustained sperm transport is between 6 and $12 \mathrm{~h}$ (Hunter and Wilmut, 1983; Wilmut and Hunter, 1984;
Hawk, 1987). Thus, the approximately 4-h interval between AI and expected ovulation is insufficient to allow for sustained sperm transport before the oocyte becomes aged. These results indicate that there may be an ideal time for insemination, probably between the 12- and 24-h periods tested in these studies, and that this time may allow both high-quality embryos and improved fertilization rates.

In sum, larger fertility trials and physiological studies are consistent with an optimal time of AI that may lie somewhere near 8 to $16 \mathrm{~h}$ before ovulation (Trimberger and Davis, 1943; Trimberger, 1944; Dransfield et al., 1998; Pursley et al., 1998; Dalton et al., 2001). Thus, we speculate that the primary reason for improved fertility in Ovsynch-56 compared with either Cosynch protocol is the improvement caused by a 16$h$ interval from the $\mathrm{GnRH} / \mathrm{LH}$ surge until AI compared with the $\mathrm{GnRH} / \mathrm{LH}$ surge and $\mathrm{AI}$ occurring at the same time resulting in a prolonged time from AI until ovulation.

In addition, there could be some variation in fertility due to the differences in time from PGF until GnRH in the 3 protocols tested in this experiment. Treatment with GnRH at $56 \mathrm{~h}$ after PGF is likely to reduce the size of the ovulatory follicle compared with Cosynch72 (earlier timing of the LH surge), but increase the size of ovulatory follicle compared with Cosynch-48 (later LH surge). The effect of this potential change in follicle size by changing the time from PGF to GnRH is unclear because many cows treated with Ovsynch were found to ovulate a follicle that was too small $(28.7 \%$; $179 / 622)$ or too large $(22.5 \%$; $140 / 622$; Souza 
et al., 2007). In addition, a slightly longer time with lower circulating progesterone and higher circulating estrogen may also be positive for fertility (Peters and Pursley, 2003). Therefore, future trials will be needed to definitively determine whether some of the improvement found with Ovsynch-56 is related to improved timing from PGF to GnRH as well as GnRH until AI.

Overall, these results indicate that, although management may be easier using a Cosynch protocol, it does not make physiological sense to combine a protocol that precisely synchronizes the time of ovulation (within an $\sim 8$-h window) with a predetermined time of AI that is very likely to be suboptimal (Cosynch). Our results are also consistent with any recommendation of Cosynch as a reproductive management protocol in dairy herds being combined with a clear explanation of the likely reduction in P/AI compared with more-optimized protocols such as Ovsynch- 48 or Ovsynch-56. Based on the results of this study, the expected reduction is quite substantial [e.g., $36.0 \%$ (Ovsynch-56) vs. $22.9 \%$ (Cosynch-72) or $25.2 \%$ (Cosynch48); from results of second pregnancy diagnosis in Table 2]. Thus, a straightforward change from Cosynch72 or Cosynch-48 to Ovsynch-56 might be expected to produce substantial improvement in reproductive efficiency on a dairy farm.

Two previous studies (Mawhinney et al., 1999; Peters et al., 1999) have reported results with a protocol similar to the Ovsynch-56 protocol utilized in this study ( $\mathrm{GnRH}$ administration at 56 to $60 \mathrm{~h}$ after $\mathrm{PGF}_{2 \alpha}$ and $\mathrm{AI}$ at $72 \mathrm{~h}$ in dairy cattle). One of those studies (Peters et al., 1999) evaluated synchrony of ovulation when all animals received GnRH $7 \mathrm{~d}$ before an injection of $\mathrm{PGF}_{2 \alpha}$ and then received no further treatment, GnRH at 56 to $60 \mathrm{~h}$ following $\mathrm{PGF}_{2 \alpha}$, or $\mathrm{GnRH}$ at 72 $\mathrm{h}$ after $\mathrm{PGF}_{2 \alpha}$. With 11,11 , and 10 cows per group, respectively, the authors concluded that GnRH administration between 56 and $60 \mathrm{~h}$ following $\mathrm{PGF}_{2 \alpha}$ administration resulted in the tightest synchrony of ovulation, with all but one animal ovulating between 72 and $96 \mathrm{~h}$ after $\mathrm{PGF}_{2 \alpha}$. The other study (Mawhinney et al., 1999) compared an Ovsynch-56 TAI protocol to AI following detected estrus. The purpose of that study was to evaluate whether using that regimen would advance the calving period under UK farm conditions. The results indicated that although overall P/AI was greater for the control animals (52.0 vs. $44.0 \%$; control vs. treatment, respectively), the calving to conception interval was, in fact, decreased $(\sim 15 \mathrm{~d} ; P<0.005)$ for the treated animals compared with the control group. Obviously, this improvement in reproductive efficiency is due to improvements in service rate (percentage of cows receiving AI during 21-d intervals). Thus, the results of these previous studies combined with the results of this study provide strong support for the efficiency of Ovsynch-56 as a reproductive management protocol.

In our study a greater percentage of animals became pregnant at first service compared with later services (overall P/AI: 34.7 vs. $27.2 \%$ ), probably due to the presynchronization of cows with $2 \mathrm{PGF}_{2 \alpha}$ treatments before first AI. A number of studies have found improvements in $\mathrm{P} / \mathrm{AI}$ when cows receive 2 injections of $\mathrm{PGF}_{2 \alpha}$ given $14 \mathrm{~d}$ apart followed by either 12 or $14 \mathrm{~d}$ from the second $\mathrm{PGF}_{2 \alpha}$ to the initiation of Ovsynch (Moreira et al., 2001; Navanukraw et al., 2004). This protocol may increase the number of cows in the middle of the estrous cycle at the time Ovsynch is initiated, which has been shown to be a more optimal time to initiate Ovsynch compared with the early or late estrous cycle (Vasconcelos et al., 1999). Our protocol utilized an 11$\mathrm{d}$ interval from the second $\mathrm{PGF}_{2 \alpha}$ injection until the first GnRH of Ovsynch. Although we did not determine cyclicity status in this study, cycling cows would be expected to express estrus between 2 and $6 \mathrm{~d}$ after $\mathrm{PGF}_{2 \alpha}$ and therefore should be at $\mathrm{d} 5$ to 9 of the estrous cycle at the initiation of Ovsynch, an optimal time to ovulate a follicle in response to the first $\mathrm{GnRH}$ injection. Surprisingly, the dramatic improvements in $\mathrm{P} /$ $\mathrm{AI}$ at first service (12 to $14 \%$ ) were only observed for the Cosynch-48 and Ovsynch-56 groups, but not for the Cosynch-72 group. It is unclear why our results contrast with the results of Portaluppi and Stevenson (2005) reporting that Cosynch-72 was superior to other groups during the first-service breedings.

There was also superior overall P/AI in primiparous compared with multiparous cows (36.9 vs. $25.4 \%$; LSM calculated regardless of treatment) consistent with a number of previous studies (Stevenson et al., 1996; Cartmill et al., 2001; Tenhagen et al., 2001, 2004; Peters and Pursley, 2002; Sterry et al., 2007) but not all trials (Jobst et al., 2000; Tenhagen et al., 2003). But again, the parity differences (9- to 11-percentage-point differences) were only observed in the Cosynch-48 and Ovsynch-56 groups, not in the Cosynch-72 group (Table 4). Nevertheless, there were numerically better P/ AI for primiparous compared with multiparous cows in the Cosynch-72 group suggesting that there may only be a quantitative, not a qualitative, difference between parities in their response to these treatment alterations. Interestingly, all of the parity effects in this study appear to be due to improved P/AI in primiparous cows during first service. Surprisingly, there was no difference in P/AI between primiparous and multiparous animals at later services (Figure 1).

Although this study provided many intriguing results, it should not be overinterpreted because only a limited number of treatment groups were evaluated. 
For example, this study did not include comparisons of multiple intervals between the final GnRH injection of Ovsynch and $\mathrm{AI}$ and therefore does not address the question of whether $16 \mathrm{~h}$ after $\mathrm{GnRH}$ is superior to other times such as AI at 8 or $24 \mathrm{~h}$ after GnRH. In addition, the design of this study allowed us to validly compare Cosynch-72 to the Ovsynch-56 protocol but did not provide information on whether Ovsynch-56 is superior to the traditional Ovsynch protocol $(\mathrm{GnRH}$ $48 \mathrm{~h}$ after $\mathrm{PGF}_{2 \alpha}$ and $\mathrm{AI} 16 \mathrm{~h}$ after $\mathrm{GnRH}$ ). Finally, this study did not evaluate a Cosynch-56 protocol. Future studies may provide more insight into the flexibility that is possible with this protocol so that it can be optimally adapted to the labor and facility situation on each dairy farm.

In conclusion, the results of this study provide evidence that the Ovsynch-56 protocol provides an increase in fertility compared with either Cosynch- 48 or Cosynch-72. Further studies will be needed to determine if the improvements were due to the change in time from PGF to GnRH or GnRH to AI and whether the Ovsynch-56 protocol will provide improved fertility at all times of the year, including during summer heat stress. Nevertheless, the dramatic improvement in fertility, as measured by P/AI, by using Ovsynch-56 (38.6\%) compared with Cosynch-48 (29.2\%) and Cosynch-72 (25.4\%), is likely to offset any increase in labor costs needed to implement this change. The difficulty for dairy managers in implementing Ovsynch56 will be handling cows in both the morning and evening during reproductive management protocols.

\section{REFERENCES}

Caraviello, D. Z., K. A. Weigel, P. M. Fricke, M. C. Wiltbank, M. J. Florent, N. B. Cook, K. V. Nordlund, N. R. Zwald, and C. L. Rawson. 2006. Survey of management practices on reproductive performance of dairy cattle on large US commercial farms. J. Dairy Sci. 89:4723-4735.

Cartmill, J. A., S. Z. El-Zarkouny, B. A. Hensley, G. C. Lamb, and J. S. Stevenson. 2001. Stage of cycle, incidence, and timing of ovulation, and pregnancy rates in dairy cattle after three timed breeding protocols. J. Dairy Sci. 84:1051-1059.

Cornwell, J. M., M. L. McGilliard, R. Kasimanickam, and R. L. Nebel. 2006. Effect of sire fertility and timing of artificial insemination in a Presynch + Ovsynch protocol on first-service pregnancy rates. J. Dairy Sci. 89:2473-2478.

Dalton, J. C., S. Nadir, J. H. Bame, M. Noftsinger, R. L. Nebel, and R. G. Saacke. 2001. Effect of time of insemination on number of accessory sperm, fertilization rate, and embryo quality in nonlactating dairy cattle. J. Dairy Sci. 84:2413-2418.

Dransfield, M. B. G., R. L. Nebel, R. E. Pearson, and L. D. Warnick. 1998. Timing of insemination for dairy cows identified in estrus by a radiotelemetric estrus detection system. J. Dairy Sci. 81:1874-1882.

Geary, T. W., and J. C. Whittier. 1998. Effect of a timed insemination following synchronization of ovulation using the Ovsynch or CoSynch protocol in beef cows. Prof. Anim. Sci. 14:217-220.

Hawk, H. W. 1987. Transport and fate of spermatozoa after insemination of cattle. J. Dairy Sci. 70:1487-1503.
Hunter, R. H. F., and I. Wilmut. 1983. The rate of functional sperm transport into the oviducts of mated cows. Anim. Reprod. Sci. 5:167-173.

Jobst, S. M., R. L. Nebel, M. L. McGilliard, and K. D. Pelzer. 2000. Evaluation of reproductive performance in lactating dairy cows with prostaglandin $\mathrm{F}_{2 \alpha}$. J. Dairy Sci. 83:2366-2372.

Mawhinney, I., H. Biggadike, and B. Drew. 1999. Field trial of a planned breeding regimen for dairy cows, using gonadotrophinreleasing hormone and prostaglandin $\mathrm{F}_{2 \alpha}$. Vet. Rec. 145:551554.

Moreira, F., C. Orlandi, C. A. Risco, R. Mattos, F. Lopes, and W. W. Thatcher. 2001. Effects of presynchronization and bovine somatotropin on pregnancy rates to a timed artificial insemination protocol in lactating dairy cows. J. Dairy Sci. 84:1646-1659.

Navanukraw, C., D. A. Redmer, L. P. Reynolds, J. D. Kirsch, A. T. Grazul-Bilska, and P. M. Fricke. 2004. A modified presynchronization protocol improves fertility to timed artificial insemination in lactating dairy cows. J. Dairy Sci. 87:1551-1557.

NRC. 2001. Nutrient Requirements of Dairy Cattle. 7th rev. ed. Natl. Acad. Sci., Washington, DC.

Peters, A. R., I. Mawhinney, S. B. Drew, S. J. Ward, M. J. Warren, and P. J. Gordon. 1999. Development of a gonadotrophin-releasing hormone and prostaglandin regimen for the planned breeding of dairy cows. Vet. Rec. 145:516-521.

Peters, M. W., and J. R. Pursley. 2002. Fertility of lactating dairy cows treated with Ovsynch after pre-synchronization injections of $\mathrm{PGF}_{2 \alpha}$ and GnRH. J. Dairy Sci. 85:2403-2406.

Peters, M. W., and J. R. Pursley. 2003. Timing of final GnRH of the Ovsynch protocol affects ovulatory follicle size, subsequent luteal function, and fertility in dairy cows. Theriogenology 60:1197-1204.

Portaluppi, M. A., and J. S. Stevenson. 2005. Pregnancy rates in lactating dairy cows after presynchronization of estrous cycles and variations of the Ovsynch protocol. J. Dairy Sci. 88:914-921.

Pursley, J. R., M. O. Mee, and M. C. Wiltbank. 1995. Synchronization of ovulation in dairy cows using $\mathrm{PGF}_{2 \alpha}$ and $\mathrm{GnRH}$. Theriogenology 44:915-923.

Pursley, J. R., R. W. Silcox, and M. C. Wiltbank. 1998. Effect of time of artificial insemination on pregnancy rates, calving rates, pregnancy loss, and gender ratio after synchronization of ovulation in lactating dairy cows. J. Dairy Sci. 81:2139-2144.

Saacke, R. G., J. C. Dalton, S. Nadir, R. L. Nebel, and J. H. Bame. 2000. Relationship of seminal traits and insemination time to fertilization rate and embryo quality. Anim. Reprod. Sci. 6061:663-677.

Souza, A. H., A. Gümen, E. P. B. Silva, A. P. Cunha, J. N. Guenther, C. M. Peto, D. Z. Caraviello, and M. C. Wiltbank. 2007. Supplementation with estradiol-17 $\beta$ before the last gonadotropin-releasing hormone injection of the ovsynch protocol in lactating dairy cows. J. Dairy Sci. 90:4623-4634.

Sterry, R. A., P. W. Jardon, B. Ryzebol, and P. M. Fricke. 2007. Effect of timing of Cosynch on fertility of lactating Holstein cows after first postpartum and Resynch timed-AI services. Theriogenology 67:1211-1216.

Stevenson, J. S., Y. Kobayashi, M. Shipka, and K. C. Rauchholz. 1996. Altering conception of dairy cattle by gonadotropin-releasing hormone preceding luteolysis induced by prostaglandin $\mathrm{F}_{2 \alpha}$. J. Dairy Sci. 79:402-410.

Tenhagen, B. A., M. Drillich, and W. Heuwieser. 2001. Analysis of cow factors influencing conception rates after two timed breeding protocols. Theriogenology 56:831-838.

Tenhagen, B. A., R. Surholt, M. Wittke, C. Vogel, M. Drillich, and W. Heuwieser. 2004. Use of Ovsynch in dairy herds-Differences between primiparous and multiparous cows. Anim. Reprod. Sci. 81:1-11.

Tenhagen, B. A., M. Wittke, M. Drillich, and W. Heuwieser. 2003. Timing of ovulation and conception rate in primiparous and multiparous cows after synchronization of ovulation with GnRH and $\mathrm{PGF}_{2 \alpha}$. Reprod. Domest. Anim. 38:451-454.

Trimberger, G. W. 1944. Conception rate in dairy cattle by artificial insemination at various intervals before and after ovulation. J. Dairy Sci. 27:659-660. 
Trimberger, G. W., and H. P. Davis. 1943. Breeding efficiency in dairy cattle bred at various stages of estrus by artificial insemination. J. Dairy Sci. 26:757-759.

Vasconcelos, J. L. M., R. W. Silcox, J. A. Lacerda, J. R. Pursley, and M. C. Wiltbank. 1997. Pregnancy rate, pregnancy loss, and response to heat stress after AI at 2 different times from ovulation in dairy cows. Biol. Reprod. 56(Suppl. 1):140.

Vasconcelos, J. L. M., R. W. Silcox, G. J. M. Rosa, J. R. Pursley, and M. C. Wiltbank. 1999. Synchronization rate, size of the ovulatory follicle, and pregnancy rate after synchronization of ovulation beginning on different days of the estrous cycle in lactating dairy cows. Theriogenology 52:1067-1078.

Walker, W. L., R. L. Nebel, and M. L. McGilliard. 1996. Time of ovulation relative to mounting activity in dairy cattle. J. Dairy Sci. 79:1555-1561.

Wilmut, I., and R. H. Hunter. 1984. Sperm transport into the oviducts of heifers mated early in oestrus. Reprod. Nutr. Dev. 24:461-468. 